\title{
Complications of Transoral Thyroidectomy: Overview and Update
}

\author{
Kyung Tae (i) \\ Department of Otolaryngology-Head and Neck Surgery, Hanyang University College of Medicine, Seoul, Korea
}

Transoral thyroidectomy via the vestibular approach has become popular worldwide, with advantages including less surgical morbidity, excellent postoperative cosmesis, and superior functional voice outcomes. Several studies have reported that the surgical outcomes of the transoral approach were comparable to those of the conventional transcervical approach in selected patients. However, unusual complications, such as $\mathrm{CO}_{2}$ embolism, mental nerve injury, surgical space infection, skin perforation, burns, and trauma have been noted in transoral thyroidectomy. This paper aims to review and provide updated information on these complications and their management. Routine intraoperative neural monitoring is required to avoid laryngeal nerve palsy in the transoral approach. To prevent $\mathrm{CO}_{2}$ embolism, surgeons need to be careful not to injure the anterior jugular vein, and the $\mathrm{CO}_{2}$ insufflation pressure should be set as low as 4-6 $\mathrm{mmHg}$. To avoid mental nerve injury, vestibular incisions should be placed in the safety zone, and dissection of the vestibular area and chin should be minimized. In conclusion, recognizing the possibility of complications and understanding their prevention and management are important for patient safety and the success of the transoral approach.

Keywords. $\mathrm{CO}_{2}$ Embolism; Complications; Mental Nerve Injuries; Vocal Cord Paralysis; Surgical Site Infection; Transoral Thyroidectomy

\section{INTRODUCTION}

Transoral thyroidectomy has been recently highlighted and adopted by many surgeons worldwide, including in Asia, Europe, North America, and Latin America, owing to its several advantages $[1,2]$. The first trial of the transoral approach was performed in 2008 using cadavers and a pig model with a central sublingual incision and two small incisions on the external neck skin [3]. Wilhelm and Metzig [4] performed the first endoscopic transoral thyroidectomy on a human using a sublingual incision for the endoscope and two lateral incisions in the oral vestibule for the endoscopic instruments. This technique was initially considered attractive and received much attention. However, it is not widely used today [5].

The transoral vestibular approach, which uses three incisions

\footnotetext{
- Received October 8, 2020

Revised November 4, 2020

Accepted November 15, 2020

- Corresponding author: KyungTae

Department of Otolaryngology-Head and Neck Surgery, Hanyang

University College of Medicine, 222-1Wangsimni-ro, Seongdong-gu,

Seoul 04763, Korea

Tel: +82-2-2290-8585, Fax: +82-2-2293-3335

E-mail: kytae@hanyang.ac.kr
}

in the oral vestibule, was first introduced by Richmon et al. [6] in 2011 with a cadaver and surgical robot. The first transoral endoscopic vestibular approach thyroidectomy in human patients was reported in China in 2014 [7,8]. However, the oral vestibular approach became widespread after Anuwong's 2016 study of 60 patients who underwent the transoral endoscopic thyroidectomy vestibular approach [9]. The feasibility of transoral thyroidectomy using the da Vinci Si surgical system (Intuitive Surgical, Sunnyvale, CA, USA) in humans was also reported by Kim et al. [10]. They utilized the three oral vestibular ports and an additional axillary port to insert the third robotic instrument. Recently, the gasless transoral endoscopic vestibular approach using an external retraction system without $\mathrm{CO}_{2}$ insufflation and transoral robotic thyroidectomy using the da Vinci singleport (SP) robot with $\mathrm{CO}_{2}$ insufflation or a gasless method were introduced [11-14]. However, further studies are necessary to determine the safety and efficacy of gasless transoral endoscopic thyroidectomy and the robotic transoral procedure using the da Vinci SP robot [15].

The transoral vestibular approach with $\mathrm{CO}_{2}$ insufflation is currently the most popular procedure in transoral thyroidectomy [7-10,16-35]. Its most significant advantages are low surgical morbidity, superior postoperative cosmesis, and good functional

Copyright @ 2021 by Korean Society of Otorhinolaryngology-Head and Neck Surgery.

This is an open-access article distributed under the terms of the Creative Commons Attribution Non-Commercial License (https://creativecommons.org/licenses/by-nc/4.0)

which permits unrestricted non-commercial use, distribution, and reproduction in any medium, provided the original work is properly cited. 
short-term voice outcomes $[1,2,36]$. The invasiveness of the transoral approach in creating a working space is less than that of other remote access thyroidectomy procedures via the axillary and breast route, because of the short distance between the oral incisions and the thyroid gland $[1,2,36]$. Postoperative cosmesis is potentially better than that of other robotic or endoscopic procedures because there is no visible neck skin scar [1]. The fact that this is a midline approach enables surgeons to perform bilateral total thyroidectomy. In addition, this approach has the advantage of enabling complete central lymph node dissection, including at levels VI and VII [1,37]. Regarding postoperative voice function, Song et al. [38] reported that transoral robotic thyroidectomy preserved the highest frequency and pitch range better than the conventional transcervical approach.

Transoral vestibular thyroidectomy is performed using endoscopy or a da Vinci surgical robot. Currently, the endoscopic procedure is more commonly performed than the robotic procedure. This is due to the advantages of the endoscopic procedure, such as shorter operative time, convenience and familiarity with the laparoscopy surgical system and instruments, and no requirement for the expensive da Vinci surgical robot $[1,15]$. Furthermore, the robotic procedure requires practice to overcome the learning curve. However, the robotic procedure using the da Vinci surgical robot also has many advantages, such as the threedimensional high-resolution magnified view, the convenient bendable tip of the robotic instruments, and the ability to use the third robotic instrument via the axillary port for countertraction [15]. In particular, countertraction is helpful for a safer and more precise dissection of the recurrent laryngeal nerve (RLN) and parathyroid glands, similar to conventional thyroidectomy.

Tae et al. [21] reported similar surgical outcomes between robotic and endoscopic procedures, except for the operative time, which was significantly longer in the robotic procedure because of the additional time required for docking and exchanging the instruments.

Several comparative studies have recently revealed that the transoral vestibular approach is feasible and safe, and its surgical outcomes are acceptable and comparable to those of the conventional transcervical approach $[18,23,26,28]$. However, the transoral vestibular approach technique has not yet been standardized, and it is still in the development stage. Confirmation

\section{H I G H L I G H T T S}

- Transoral thyroidectomy is feasible and comparable to conventional thyroidectomy.

- $\mathrm{CO}_{2}$ embolism, mental nerve injury, surgical space infection, and skin trauma can occur.

- Recognition and prevention of complications are important for patient safety. of its long-term oncologic safety and efficacy is required. The rate of traditional complications in the transoral approach, such as vocal fold paralysis, hypoparathyroidism/hypocalcemia, hematoma, and seroma, has been shown to be similar to that of conventional thyroidectomy (Table 1 ) $[4,5,7-10,13,16-20,22,24-$ $35,39]$. However, unusual complications of the transoral approach, including $\mathrm{CO}_{2}$ embolism, mental nerve injury, surgical space infection, skin perforation, burns, and trauma have been reported (Table 2) [4,5,7-10,13,16-20,22,24-35,39]. Therefore, surgeons need to be aware that unusual complications can occur during transoral thyroidectomy. It is also important to know how to prevent and manage complications properly to ensure the safety and success of surgery. This paper aims to review and provide updated information on the complications of transoral thyroidectomy and to investigate how to prevent and manage them. Written informed consent was obtained from the patients for publication of the photographs.

\section{LARYNGEAL NERVE PALSY}

According to meta-analyses, the incidence of RLN palsy in transoral thyroidectomy is acceptable and comparable with that in the conventional transcervical approach [40-43]. However, RLN injury might be more frequent in the transoral approach, especially for surgeons who are initially learning the procedure or perform a low volume of procedures. The RLN palsy rate reported in previous studies ranged from $0 \%$ to $20 \%$ for transient palsy and from $0 \%$ to $12.5 \%$ for permanent palsy (Table 1 ) [4,5,7-10,13,16-20,22,24-35,39]. Studies performed during the initial introduction period of the transoral approach reported a higher rate of RLN palsy, ranging from $12.5 \%$ to $20 \%$ [4,16,39].

The gold standard for RLN identification is direct visual identification. However, it is challenging to identify and preserve the RLN visually in the transoral approach, owing to the limited surgical space and view, although magnification of the view by the endoscope or the surgical robot helps identify the RLN. In transoral thyroidectomy, the RLN is usually identified in the laryngeal entry portion in the magnified view and confirmed using an intraoperative neural monitoring (IONM) stimulating probe. IONM is useful for identifying and confirming the RLN in the transoral approach, although there is no evidence that IONM reduces the rate of RLN palsy [44-46]. In addition, IONM facilitates mapping the RLN course and dissecting the nerve. It also helps predict postoperative RLN function, elucidate the cause of RLN injury, and improve surgical technique [44]. The success rate of IONM for the RLN in transoral thyroidectomy was reported to be $82.8 \%-100 \%$, although it might be somewhat lower than that of the conventional approach [44-46]. The success rate of IONM might be influenced by the learning curve of the transoral procedure and the learning curve of IONM [44]. For IONM to be successful, proper placement of 
Table 1. Traditional complications in transoral thyroidectomy

\begin{tabular}{|c|c|c|c|c|c|}
\hline Study & $\begin{array}{l}\text { No. of } \\
\text { cases }\end{array}$ & $\begin{array}{c}\text { RLN palsy } \\
\text { (transient/permanent) }\end{array}$ & $\begin{array}{l}\text { Hypoparathyroidism } \\
\text { (transient/permanent) }\end{array}$ & Hematoma & Seroma \\
\hline Wilhelm and Metzig (2011) [4] & 8 & $1(12.5) / 1(12.5)$ & $0 / 0$ & 0 & 0 \\
\hline Nakajo et al. (2013) [39] & 8 & $1(12.5) / 0$ & $0 / 0$ & NA & NA \\
\hline Wang et al. (2014) [7] & 12 & $0 / 0$ & $0 / 0$ & 0 & 0 \\
\hline Yang et al. (2015) [8] & 41 & $1(2.4) / 0$ & NA & NA & NA \\
\hline Anuwong (2016) [9] & 60 & $2(3.3) / 0$ & $3(5) / 0$ & $1(1.67)$ & NA \\
\hline Chai et al. (2017) [16] & 10 & $2(20) / 0$ & NA & 0 & 0 \\
\hline Dionigi et al. (2017) [17] & 15 & $0 / 0$ & $1(6.7) / 0$ & 0 & 0 \\
\hline Kim et al. (2018) [10] & 24 & $0 / 0$ & NA & 0 & 0 \\
\hline Fu et al. (2018) [5] & 81 & $0 / 0$ & $0 / 0$ & 0 & NA \\
\hline Anuwong et al. (2018) [18] & 422 & $25(5.9) / 0$ & $46(10.9) / 0$ & $1(0.2)$ & $20(4.7)$ \\
\hline Bian et al. (2018) [19] & 30 & $0 / 0$ & $0 / 0$ & 0 & 0 \\
\hline Razavi et al. (2018) [20] & 27 & $1(3.7) / 0$ & $0 / 0$ & 0 & 0 \\
\hline Russell et al. (2019) [22] & 92 & $4(4.3) / 0$ & $0 / 0$ & 0 & $1(1.1)$ \\
\hline Perez-Soto et al. (2019) [24] & 20 & $2(10) / 1(5)$ & $5(25) / 0$ & $1(5)$ & NA \\
\hline Park et al. (2019) [25] & 65 & $2(3.1) / 1(1.5)$ & $5(7.7) / 0$ & 0 & $4(8.5)$ \\
\hline Park et al. (2019) [13] & 10 & $0 / 0$ & $0 / 0$ & 0 & $1(10)$ \\
\hline Tae et al. (2020) [26] & 100 & $5(5) / 0$ & $7(30.4) / 1(4.3)$ & $1(1)$ & $13(13)$ \\
\hline Peng et al. (2020) [27] & 105 & $3(2.9) / 2(1.9)$ & $2(1.9) / 0$ & 0 & $3(2.9)$ \\
\hline Ahn and Yi (2020) [28] & 150 & $7(4.7) / 1(0.7)$ & $5(3.3) / 2(1.3)$ & $1(0.7)$ & $2(1.3)$ \\
\hline Park et al. (2020) [29] & 200 & $2(1.0) / 0$ & 1 (out of $13,7.7) / 0$ & $1(0.5)$ & 0 \\
\hline Hong et al. (2020) [30] & 82 & $3(3.7) / 0$ & $1(1.2) / 0$ & 0 & $2(2.4)$ \\
\hline Kim et al. (2020) [31] & 132 & $6(4.5) / 0$ & $1(12.5) / 0$ & $1(0.8)$ & $2(1.5)$ \\
\hline Kim et al. (2020) [32] & 100 & $1(1) / 0$ & $3(3) / 0$ & $2(2)$ & $2(2)$ \\
\hline Fernandez-Ranvier et al. (2020) [33] & 50 & $2(4) / 1(2)$ & $1(2) / 0$ & 0 & NA \\
\hline Lira et al. (2020) [34] & 56 & $2(3.6) / 0$ & $4(10.8) / 0$ & 0 & $1(1.8)$ \\
\hline Luna-Ortiz et al. (2020) [35] & 46 & $1(2.2) / 2(4.3)$ & $\mathrm{NA} / 2(4.3)$ & NA & NA \\
\hline
\end{tabular}

Values are presented as number (\%).

RLN, recurrent laryngeal nerve; NA, not available.

the electromyography tube is crucial.

It is challenging to perform standard IONM procedures through the transoral approach. Usually, vagus nerve stimulation is not routinely performed in robotic and endoscopic thyroidectomy, including the transoral approach, because additional time and effort are required to dissect and identify the vagus nerve [44]. In addition, vagus nerve stimulation might result in longer operative times and surgical morbidity. It was reported that the vagus nerve was identified and the signal obtained in fewer than $30 \%$ of patients who underwent a minimally invasive endoscopic procedure [46]. In a study conducted by Ji et al. [44], a vagus nerve signal was obtained in only $19 \%$ of the nerves in transoral thyroidectomy, even though they tried to follow the standard IONM procedure.

Paralysis of the external branch of the superior laryngeal nerve (EBSLN) is another interesting issue in thyroidectomy. IONM of the EBSLN is performed to obtain S1 and S2 signals in addition to the standard IONM procedure for the RLN and vagus nerve [47-49]. The identification of the EBSLN is challenging, even in conventional thyroidectomy [47]. Ji et al. [47] evaluated the feasibility and success rate of EBSLN monitoring in transoral robotic and endoscopic thyroidectomy. They found that the monitor- ing success of EBSLN was $42.5 \%$, and the success rate did not differ between the robotic and endoscopic procedures [47]. The low success rate of IONM for the EBSLN in the transoral approach might be related to the difficulty of identifying and stimulating the EBSLN in the limited surgical space and angle of the view, especially if the EBSLN passes inside the inferior pharyngeal constrictor or runs into the larynx at a higher level $[47,50]$. However, IONM of the EBSLN helps identify and preserve the nerve and dissect the superior pole despite the low identification rate. Even if identification of the EBSLN using IONM is not possible, surgeons can cut the superior thyroid vessel safely after confirming that it is not the EBSLN using IONM [47].

In the transoral approach, it is challenging to follow the troubleshooting instructions for a loss of signal. Surgeons cannot palpate laryngeal twitching, and stimulation of the contralateral vagus nerve is also difficult. However, surgeons could check laryngeal twitching using the magnified endoscopic view as an alternative method [44].

Regarding the stimulating probe, the robotic and endoscopic instruments are connected to the interface-connector box by a cable. A long shaft stimulating probe and cut ground needle are used as the stimulating probe in the transoral approach $[44,51]$. 


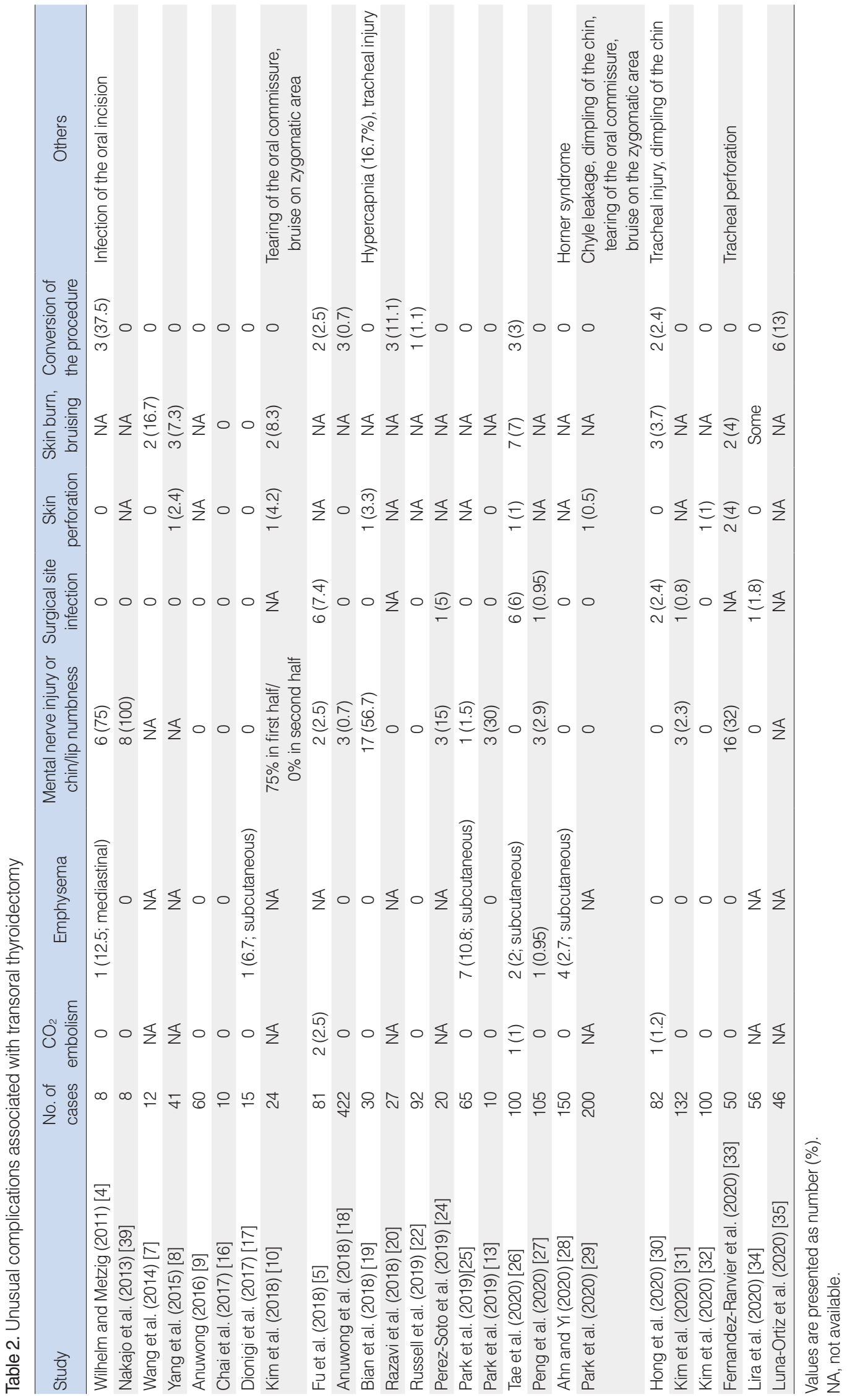


In addition, a standard stimulating probe can be used through a percutaneous puncture. In conclusion, IONM needs to be used routinely to confirm and preserve the RLN and EBSLN in transoral thyroidectomy, though it does have some limitations.

\section{$\mathrm{CO}_{2}$ EMBOLISM}

$\mathrm{CO}_{2}$-associated complications, such as $\mathrm{CO}_{2}$ embolism, emphyse$\mathrm{ma}$, and hypercapnia, can occur in the transoral vestibular approach using $\mathrm{CO}_{2}$ insufflation $[1,52]$. The rate of $\mathrm{CO}_{2}$ embolism in transoral thyroidectomy has been reported to be very low. Only four cases of $\mathrm{CO}_{2}$ embolism have been reported in the literature (Table 2) $[5,26,30]$. However, the actual incidence of $\mathrm{CO}_{2}$ embolism in transoral thyroidectomy might be higher than reported or expected. Bian et al. [19] reported that hypercapnia occurred in $16.7 \%$ of patients during transoral endoscopic thyroidectomy.

The clinical presentation of $\mathrm{CO}_{2}$ embolism ranges from a lack of symptoms to neurological sequelae, cardiovascular collapse, or even death, depending on the volume of $\mathrm{CO}_{2}$ entering the circulation [53]. $\mathrm{CO}_{2}$ micro-embolism or hypercapnia that might be asymptomatic or self-resolving without significant clinical symptoms can occur quite often. In a study that investigated the incidence of $\mathrm{CO}_{2}$ embolism in laparoscopic total hysterectomy, $\mathrm{CO}_{2}$ embolism was detected in $100 \%$ of patients using transesophageal echocardiography, although no patient showed any hemodynamic instability or clinical symptoms [54].

In transoral thyroidectomy, $\mathrm{CO}_{2}$ embolism usually develops during elevation of the skin flap due to accidental injury to the anterior jugular vein leading to entry of $\mathrm{CO}_{2}$ into the vessel and systemic circulation [26,52]. Kim et al. [52] reported a case of severe $\mathrm{CO}_{2}$ embolism that led to cardiac arrest requiring resuscitation during skin flap elevation in transoral thyroidectomy. Fu et al. [5] reported two cases of $\mathrm{CO}_{2}$ embolism that presented with a sudden decrease in blood pressure and oxygen saturation while creating the working space during the procedure and required external chest compression. Hong et al. [30] reported a case of $\mathrm{CO}_{2}$ embolism that occurred just after the placement of a central oral trocar and $\mathrm{CO}_{2}$ insufflation. This might have been a consequence of injuring the superficial vessels while inserting a long dilator for blunt dissection of the anterior neck. Therefore, to prevent $\mathrm{CO}_{2}$ embolism, special care should be taken to avoid injury to the anterior jugular vein and superficial vessels. It is crucial to minimize blunt dissection of the neck using a long blunt dilator to reduce the chance of tearing and injuring the vessels. Blunt dissection should be performed only in the submental area. In addition, the skin flap should be elevated precisely through the subplatysmal layer under endoscopic guidance $[21,26]$. Moreover, the $\mathrm{CO}_{2}$ insufflation pressure should be set as low as 4-6 mmHg, and the $\mathrm{CO}_{2}$ flow rate must be lower than $8-10 \mathrm{~L} / \mathrm{min}$ [26]. If the anterior jugular vessels are torn during the transoral thyroidectomy procedure, the tear must be first compressed using cotton or gauze to prevent the entry of $\mathrm{CO}_{2}$ into the vessel. The torn vessel should then be carefully sealed off using bipolar coagulation, an energy device, or vessel clips.

If $\mathrm{CO}_{2}$ embolism is clinically suspected, $\mathrm{CO}_{2}$ gas insufflation should be stopped, and 100\% oxygen should be administered $[52,53]$. Administration of $100 \%$ oxygen helps remove $\mathrm{CO}_{2}$ and improve hypoxemia and ventilation-perfusion mismatch [53]. The patient needs to be positioned in the left lateral decubitus position and reverse Trendelenburg position to direct the gas bubbles into the right ventricle. Hyperventilation can also be used to help eliminate $\mathrm{CO}_{2}$. Cardiac resuscitation including inotropic agents, vasopressors, and chest compression may be necessary for patients with cardiac arrest or severe cardiovascular collapse [52,53].

\section{EMPHYSEMA}

Subcutaneous emphysema can develop after transoral thyroidectomy, usually in the neck, face, and upper chest. The incidence of subcutaneous emphysema in transoral thyroidectomy has been reported to be between $2 \%$ and $10.8 \%$ [17,25,26,28]. In most cases, subcutaneous emphysema resolves spontaneously with conservative management. The possible causes of subcutaneous emphysema may include high $\mathrm{CO}_{2}$ pressure and a long operative time [26]. Therefore, surgeons need to reduce $\mathrm{CO}_{2}$ insufflation pressure and the operative time to reasonable levels to prevent the development of emphysema. Mediastinal emphysema can occur after transoral thyroidectomy [4]. In addition, a case of pneumoperitoneum after transoral endoscopic thyroidectomy was recently reported [55].

\section{MENTAL NERVE INJURY}

Mental nerve injury is a unique complication of the transoral approach. The incidence of mental nerve injury is quite diverse, ranging from $0 \%$ to $100 \%$ in previous studies (Table 2) [4,5,7$10,13,16-20,22,24-35,39]$. During the initial introduction period of the transoral thyroidectomy procedure, the rate of mental nerve injury was reported to be very high, ranging from $75 \%$ to $100 \%$, probably due to the learning curve $[4,10,39]$. However, recent studies have shown relatively lower rates of mental nerve injury, ranging from $0 \%$ to $56.7 \%$, although it is still high in some papers reporting early experiences (Table 2) [16-35]. Fernandez-Ranvier et al. [33] recently reported that the incidence of numbness of the lower lip and chin were $32 \%$ and $26 \%$, respectively, with $2 \%$ of patients sustaining a permanent injury. Another study reported transient numbness of the chin in $56.7 \%$ of cases after transoral endoscopic thyroidectomy [19]. 
In addition, Park et al. [13] reported that $30 \%$ of cases had lower lip numbness after gasless SP transoral thyroidectomy using the da Vinci SP robot.

The definition of mental nerve injury is not well established. Mental nerve injury is generally evaluated according to the patient's subjective response without any objective parameters. The definition of mental nerve injury may vary from mild sensory disturbance or paresthesia to complete sensory loss in the chin and lower lip innervated by the mental nerve. Tae et al. [56] objectively investigated mental nerve injury before and after transoral thyroidectomy. They evaluated the lower lip, chin, cheek, and neck sensitivity using the Semmes-Weinstein monofilament test. They found that the mean pressure thresholds of the chin and lower lip were not significantly different preoperatively and postoperatively. However, approximately $10 \%$ of the patients displayed transient mild sensory disturbance on the chin 1 week after the procedure [56]. These results might provide evidence that mental nerve injury rarely occurs during transoral thyroidectomy if the procedure is performed properly.

The central and lateral oral vestibular incisions should be placed in the safety zone. Therefore, the central vestibular incision needs to be made at the base of the lower lip frenulum $[21,26,56]$. If the central incision is placed at a higher level, close to the lip vermilion, the medial inferior labial branches might be injured. Zhang et al. [57] reported in a cadaveric study that the medial branch could be cut in $12 \%-25 \%$ of cases if a 10 -mm median vestibular incision was made at the high level of the lower lip. Therefore, they suggested placing the central vestibular incision more inferiorly or vertically to avoid medial branch injury. Yang et al. [58] also suggested a safety zone for the central vestibular incision composed of a triangular-shaped area with a base $3 \mathrm{~cm}$ in length in the central oral vestibule.

The lateral vestibular incisions were made relatively close to the central incision in the initial period of the transoral approach, which was associated with a higher rate of mental nerve injury $[9,10]$. Therefore, lateral incisions should be made as close as possible to the oral commissure to avoid mental nerve injury. Such incisions also provide a wide angle between the central endoscope and the two lateral robotic or endoscopic instruments, improving the manipulation of the instruments and resulting in fewer collisions [56].

A recent study conducted by King et al. [59] revealed anatomic variations of the mental nerve branches based on the dissection of 120 mental nerves using cadavers. They reported eight distinct categories of branching patterns of the mental nerve, three of which were newly described. Therefore, they recommended placing the lateral vestibular incisions $3-3.5 \mathrm{~cm}$ from the midline, lateral to the mental foramen. They also suggested the possibility of medial branch injury by the central vestibular incision because a dense clustering of mental nerve branches running toward the midline area was present in $9.2 \%$ of cases [59]. In addition to the direct injury of the mental

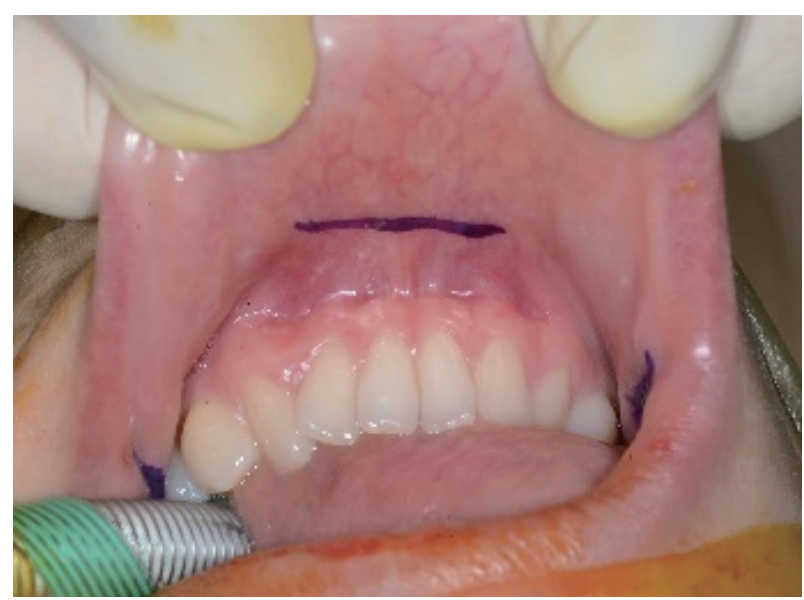

Fig. 1. Oral vestibular incisions in transoral thyroidectomy. A 1.5- to 2-cm central incision was made near the base of the lower lip frenulum, and two lateral incisions were made close to the oral commissure to avoid mental nerve injury.

nerve, the mental nerve can be damaged by increased mechanical stretching and compression due to the large trocar, forceful trocar insertion and movement, and long operative time [56].To avoid mental nerve damage, surgeons need to be aware of the possibility of mental nerve injury, place the oral vestibular incisions in the safe area, and minimize the dissection of the chin and central vestibular area (Fig. 1).

\section{SURGICAL SITE INFECTION}

Another complication reported with the transoral approach is surgical site infection. In transoral thyroidectomy, surgical site infection may be caused by various bacteria in the oral cavity, including the normal flora. However, the rates of surgical site infection reported in previous studies, including meta-analyses, are very low, ranging from $0.1 \%$ to $1 \%$ [40-43]. In contrast, Tae et al. [26] reported a relatively high surgical site infection rate after transoral robotic and endoscopic thyroidectomy. They reported that surgical site infections occurred in $6 \%$ of patients, despite routine antibiotics for 1 to 2 weeks, both preoperatively and postoperatively (Fig. 2). Fu et al. [5] also reported surgical site infections in $7.4 \%$ of patients after transoral endoscopic thyroidectomy. Surgical site infection is not well defined or standardized. Some studies included only severe cases of infection, and, therefore, the incidence of surgical site infection was low. However, Tae et al. [26] included all cases of inflammation, including mild swelling and skin redness. Therefore, the rate of infection was relatively high in their study.

Observations from our previous study led to the speculation that surgical site infections often occurred when the same suction instruments were used in both the mouth and the surgical space for transoral thyroidectomy. However, this practice is no 


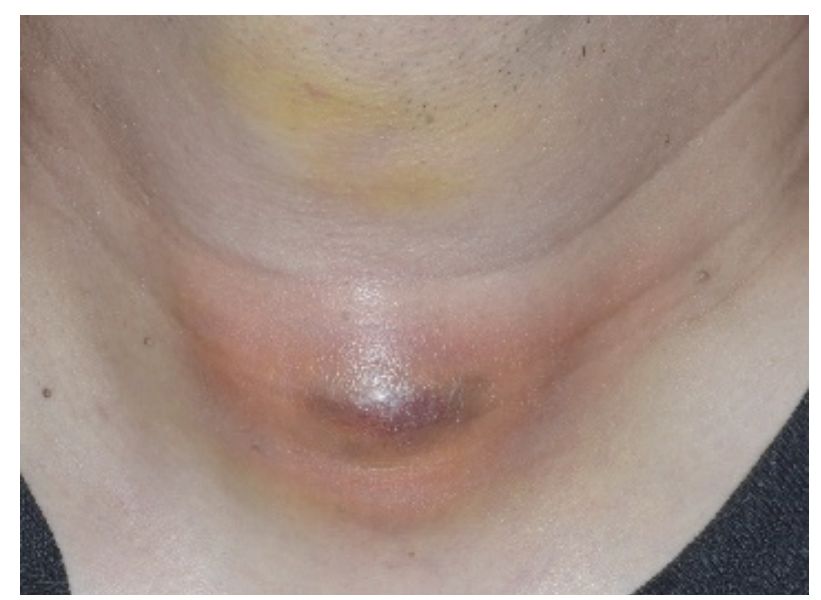

Fig. 2. Surgical space infection after transoral robotic thyroidectomy showing skin redness, swelling, and tenderness. The infection resolved with appropriate antibiotics and aspiration.

longer followed, which seems to have significantly decreased the rate of surgical site infections. Further studies are required to confirm the exact causes of surgical site infections and to suggest ways of preventing and managing them. One should nevertheless be aware of the possibility of surgical site infection after transoral thyroidectomy [26]. To prevent surgical site infection, the operating space should be treated antiseptically and irrigated with saline to remove blood clots, burned tissue, and other debris. In addition, appropriate antibiotics might be necessary preoperatively and postoperatively.

Recently, Yi et al. [60] evaluated the effectiveness of antibiotics in 25 patients who underwent transoral endoscopic thyroidectomy. They compared inflammation-related parameters, such as temperature, pulse rate, leukocytes, and C-reactive protein levels according to whether patients received postoperative antibiotics. There was no significant difference between the two groups, and they concluded that oral antibiotics are not necessary after transoral endoscopic thyroidectomy [60]. However, their study had some limitations. Therefore, caution should be exercised when interpreting the results. Further studies are necessary to determine the role of antibiotics in transoral thyroidectomy.

In addition to infection of the surgical space, dehiscence and infection of the central oral vestibular incision site can occur [4]. However, this problem usually resolves with conservative management.

\section{SKIN PERFORATION, BURN, TRAUMA, AND BRUISING}

Skin flap perforation in the anterior neck area, lower lip, and chin can occur in transoral thyroidectomy $[8,10,19,26,29,32,33]$. Perforation of the lower lip or chin might occur if the central

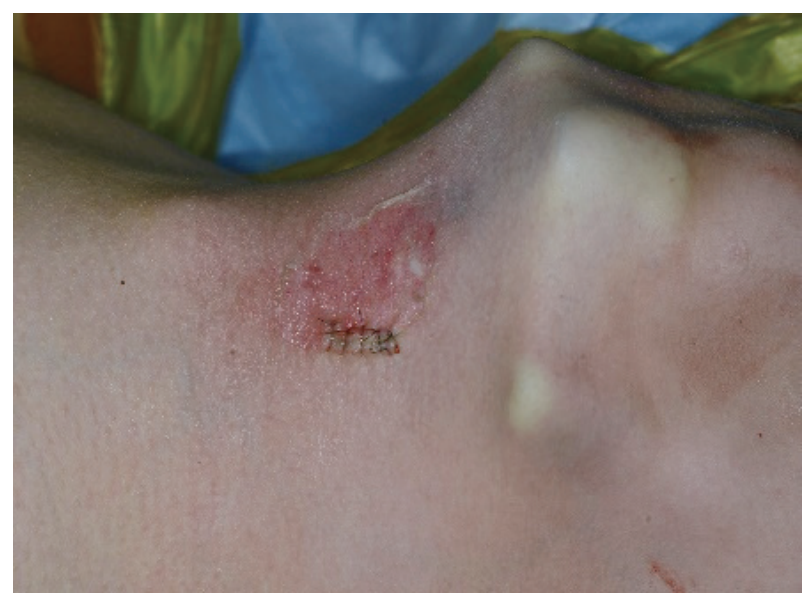

Fig. 3. Surgical view of skin perforation and trauma, which resulted in skin necrosis. A local flap was used to cover it.

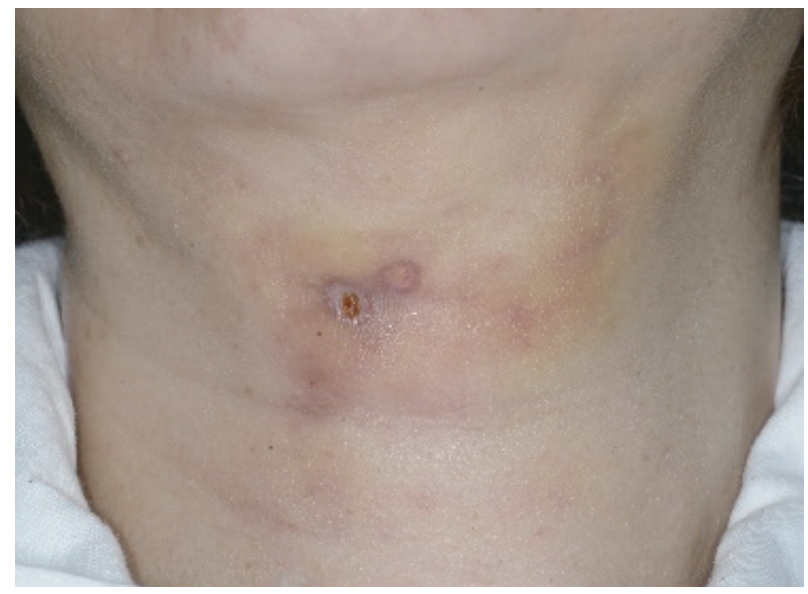

Fig. 4. Skin burn and trauma after transoral thyroidectomy, which resolved without any sequelae.

vestibular incision is placed at the upper part of the oral vestibule near the vermilion border and dissection of the soft tissue is carried out superficially using a monopolar Bovie instrument. It can also occur while inserting the lateral oral trocars, especially in patients with thin subcutaneous tissue at the premandibular area. Therefore, the lower lip skin flap needs to be elevated over the mandibular periosteum to prevent perforation of the lower lip and chin $[21,26]$. It can also be used to prevent dimpling on the chin, which is usually related to damage to the chin area's soft tissue. The anterior neck skin can also be perforated if the skin flap is elevated superficially, close to the skin, using monopolar electrocautery (Fig. 3). Care should be taken to avoid perforation of the skin when elevating the skin flap or when inserting the lateral oral trocars.

The skin can be burned or damaged due to heat from the endoscope tip or monopolar Bovie instrument, as well as mechanical trauma [26]. Most skin burns and trauma are mild and re- 


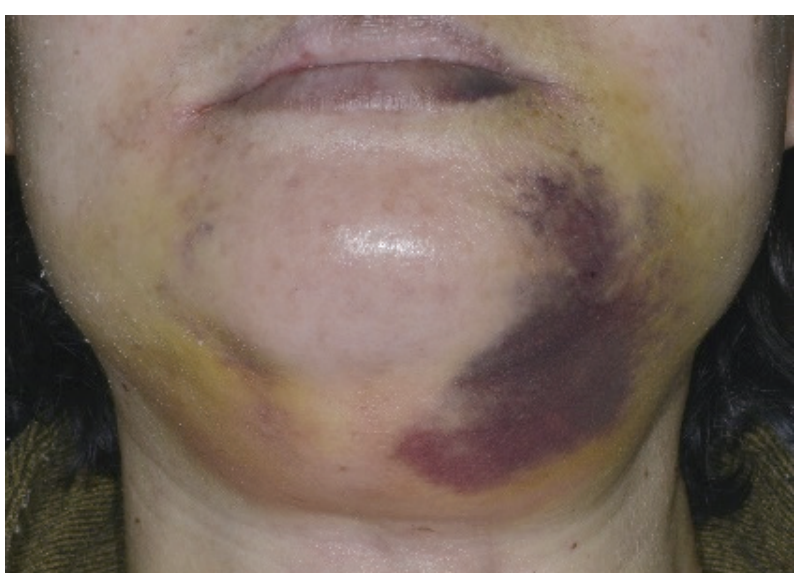

Fig. 5. Skin ecchymosis and bruising after transoral thyroidectomy.

solve without sequelae (Fig. 4). However, some severe burns and trauma can cause contracture, irregularity, and dimpling of the skin. Sometimes, severe skin burns and trauma result in skin necrosis and require coverage using a local flap. Skin ecchymosis and bruising can occur after transoral thyroidectomy (Fig. 5). However, most bruises and ecchymoses spontaneously resolve $1-2$ weeks after surgery.

\section{OTHER UNUSUAL COMPLICATIONS}

Sometimes, other unusual complications, such as tracheal perforation, dimpling of the chin, Horner syndrome, and chyle leakage, occur in transoral thyroidectomy. Tracheal perforation occurs due to the monopolar Bovie or energy device, or puncture with a Veress needle $[19,30,33]$. Minor tracheal injuries can be sutured under an endoscopic view. However, major tracheal injury might require conversion to the conventional approach. Dimpling of the chin can also occur $[29,30]$. Usually, dimpling occurs because of trauma to the soft tissue of the chin. Therefore, to prevent dimpling of the chin, surgeons need to avoid extensive soft tissue dissection of the chin, and should elevate the skin flap in the deep plane over the periosteum of the mandible to make a thick skin flap [26].

In addition, some cases of oral commissure tearing and bruising of the zygomatic area have been reported [29]. These are usually caused by the mechanical force or pressure exerted by the da Vinci surgical robot. Oral commissure tearing occurs when the robotic arm and instruments are moved vigorously over a wide range. If the robotic arms and instruments are manipulated like in the laparoscopic technique, they move in a wide range of motion and can injure the surrounding structures. Therefore, surgeons need to learn to manipulate only the tip of the robotic instruments (second joint of the robotic arm) to avoid a wide motion of the robotic arm in the transoral robotic procedure. Horner syndrome has been reported in the transoral endoscopic vestibular approach in rare cases [28].

\section{CONVERSION OFTHE PROCEDURE}

Sometimes, transoral vestibular thyroidectomy procedures need to be converted to the conventional approach or other remote access approaches. The conversion rate ranges from $0 \%$ to $37.5 \%$ [4,5,18,20,22,26,30,35]. The most common cause of conversion is uncontrollable intraoperative bleeding. In addition, $\mathrm{CO}_{2}$ embolism, inability to remove the entire tumor, and tracheal injury have been reported as causes of conversion $[5,26,30]$.

\section{CONCLUSION}

Transoral vestibular approach thyroidectomy using endoscopy or the da Vinci surgical robot is feasible and safe for selected patients. However, unusual complications, such as $\mathrm{CO}_{2}$ embolism, mental nerve injury, surgical site infection, skin perforation, burns, and trauma have been reported in addition to traditional complications, such as RLN palsy. It is important to recognize the possibility of complications and know how to prevent and manage them to ensure the safety and success of surgery. Appropriate patient selection is also crucial to avoid complications.

\section{CONFLICT OF INTEREST}

No potential conflict of interest relevant to this article was reported.

\section{ORCID}

KyungTae https://orcid.org/0000-0002-0382-2072

\section{REFERENCES}

1. Tae K, Ji YB, Song CM, Ryu J. Robotic and endoscopic thyroid surgery: evolution and advances. Clin Exp Otorhinolaryngol. 2019 Feb; 12(1):1-11.

2. Tae K.Transoral thyroidectomy: is it a real game changer? Clin Exp Otorhinolaryngol. 2020 May;13(2):93-4.

3. Witzel K, von Rahden BH, Kaminski C, Stein HJ.Transoral access for endoscopic thyroid resection. Surg Endosc. 2008 Aug;22(8):1871-5.

4. Wilhelm T, Metzig A. Endoscopic minimally invasive thyroidectomy (eMIT): a prospective proof-of-concept study in humans. World J Surg. 2011 Mar;35(3):543-51.

5. Fu J, Luo Y, Chen Q, Lin F, Hong X, Kuang P, et al.Transoral endoscopic thyroidectomy: review of 81 cases in a single institute. J Laparoendosc Adv Surg Tech A. 2018 Mar;28(3):286-91.

6. Richmon JD, Holsinger FC, Kandil E, Moore MW, Garcia JA, Tufano RP. Transoral robotic-assisted thyroidectomy with central neck dis- 
section: preclinical cadaver feasibility study and proposed surgical technique. J Robot Surg. 2011 Dec;5(4):279-82.

7. Wang C, Zhai H, Liu W, Li J, Yang J, Hu Y, et al. Thyroidectomy: a novel endoscopic oral vestibular approach. Surgery. 2014 Jan;155(1): 33-8.

8. Yang J, Wang C, Li J, Yang W, Cao G, Wong HM, et al. Complete endoscopic thyroidectomy via oral vestibular approach versus areola approach for treatment of thyroid diseases. J Laparoendosc Adv Surg Tech A. 2015 Jun;25(6):470-6.

9. Anuwong A.Transoral endoscopic thyroidectomy vestibular approach: a series of the first 60 human cases. World J Surg. 2016 Mar;40(3): 491-7.

10. Kim HY, Chai YJ, Dionigi G, Anuwong A, Richmon JD. Transoral robotic thyroidectomy: lessons learned from an initial consecutive series of 24 patients. Surg Endosc. 2018 Feb;32(2):688-94.

11. Park JO, Park YJ, Kim MR, Sun DI, Kim MS, Koh YW. Gasless transoral endoscopic thyroidectomy vestibular approach (gasless TOETVA). Surg Endosc. 2019 Sep;33(9):3034-9.

12. Park D, Shaear M, Chen YH, Russell JO, Kim HY,Tufano RP.Transoral robotic thyroidectomy on two human cadavers using the Intuitive da Vinci single port robotic surgical system and CO2 insufflation: preclinical feasibility study. Head Neck. 2019 Dec;41(12):4229-33.

13. Park YM, Kim DH, Moon YM, Lim JY, Choi EC, Kim SH, et al. Gasless transoral robotic thyroidectomy using the DaVinci SP system: feasibility, safety, and operative technique. Oral Oncol. 2019 Aug;95: 136-42.

14. Chan JY, Koh YW, Richmon J, Kim J, Holsinger FC, Orloff L, et al. Transoral thyroidectomy with a next generation flexible robotic system: a feasibility study in a cadaveric model. Gland Surg. 2019 Dec; 8(6):644-7.

15. Tae K. Transoral robotic thyroidectomy using the da Vinci single-port surgical system. Gland Surg. 2020 Jun;9(3):614-6.

16. Chai YJ, Chung JK, Anuwong A, Dionigi G, Kim HY, Hwang KT, et al. Transoral endoscopic thyroidectomy for papillary thyroid microcarcinoma: initial experience of a single surgeon. Ann Surg Treat Res. 2017 Aug;93(2):70-5.

17. Dionigi G, Bacuzzi A, Lavazza M, Inversini D, Boni L, Rausei S, et al. Transoral endoscopic thyroidectomy: preliminary experience in Italy. Updates Surg. 2017 Jun;69(2):225-34.

18. Anuwong A, Ketwong K, Jitpratoom P, Sasanakietkul T, Duh QY. Safety and outcomes of the transoral endoscopic thyroidectomy vestibular approach. JAMA Surg. 2018 Jan;153(1):21-7.

19. Bian C, Liu H, Yao XY,Wu SP,WuY, Liu C, et al. Complete endoscopic radical resection of thyroid cancer via an oral vestibule approach. Oncol Lett. 2018 Nov;16(5):5599-606.

20. Razavi CR, Khadem MG, Fondong A, Clark JH, Richmon JD, Tufano RP, et al. Early outcomes in transoral vestibular thyroidectomy: robotic versus endoscopic techniques. Head Neck. 2018 Oct;40(10): 2246-53.

21. Tae K, Lee DW, Song CM, Ji YB, Park JH, Kim DS, et al. Early experience of transoral thyroidectomy: comparison of robotic and endoscopic procedures. Head Neck. 2019 Mar;41(3):730-8.

22. Russell JO, Razavi CR, Garstka ME, Chen LW,Vasiliou E, Kang SW, et al. Remote-access thyroidectomy: a multi-institutional North American experience with transaxillary, robotic facelift, and transoral endoscopic vestibular approaches. J Am Coll Surg. 2019 Apr;228(4): 516-22.

23. You JY, Kim HY, Chai YJ, Kim HK, Anuwong A, Tufano RP, et al.Transoral robotic thyroidectomy versus conventional open thyroidectomy: comparative analysis of surgical outcomes in thyroid malignancies. J Laparoendosc Adv Surg Tech A. 2019 Jun;29(6):796-800.

24. Perez-Soto RH, Ponce de Leon-Ballesteros G, Montalvo-Hernandez J, Sierra-Salazar M, Pantoja Millan JP, Herrera-Hernandez MF, et al. Transoral endoscopic thyroidectomy by vestibular approach-initial experience and comparative analysis in the first reported Mexican cohort. J Laparoendosc Adv Surg Tech A. 2019 Dec;29(12):1526-31.

25. Park JO, Anuwong A, Kim MR, Sun DI, Kim MS. Transoral endoscopic thyroid surgery in a Korean population. Surg Endosc. 2019 Jul; 33(7):2104-13.

26. Tae K, JiYB, Song CM, Park JS, Park JH, Kim DS. Safety and efficacy of transoral robotic and endoscopic thyroidectomy: the first 100 cases. Head Neck. 2020 Feb;42(2):321-9.

27. Peng X, Li Z, Li H, Peng W, Zhou X, Song D, et al. The clinical application of mental nerve dissection in transoral endoscopic thyroidectomy via an oral vestibular approach. Surg Endosc. 2020 Jan;34(1): 153-8.

28. Ahn JH, Yi JW. Transoral endoscopic thyroidectomy for thyroid carcinoma: outcomes and surgical completeness in 150 single-surgeon cases. Surg Endosc. 2020 Feb;34(2):861-7.

29. Park D, Kim HY, Kim HK, You JY, Dionigi G, Russell JO, et al. Institutional experience of 200 consecutive papillary thyroid carcinoma patients in transoral robotic thyroidectomy surgeries. Head Neck. 2020 Aug;42(8):2106-14.

30. Hong YT, Ahn JH, Kim JH, Yi JW, Hong KH. Bi-institutional experience of transoral endoscopic thyroidectomy: challenges and outcomes. Head Neck. 2020 Aug;42(8):2115-22.

31. Kim SY, Kim SM, Makay O, Chang H, Kim BW, Lee YS, et al. Transoral endoscopic thyroidectomy using the vestibular approach with an endoscopic retractor in thyroid cancer: experience with the first 132 patients. Surg Endosc. 2020 Dec;34(12):5414-20.

32. Kim WW, Park CS, Lee J, Jung JH, Park HY,Tufano RP. Real scarless transoral robotic thyroidectomy using three ports without axillary incision. J Laparoendosc Adv Surg Tech A. 2020 Nov;30(11):1165-71.

33. Fernandez-Ranvier G, Meknat A, Guevara D, Taye A, Suh H, Inabnet WB 3rd.Transoral endoscopic thyroidectomy vestibular approach: a single-institution experience of the first 50 cases. Surg Innov. 2020 Oct;27(5):439-44.

34. Lira RB, Ramos AT, Nogueira RM, de Carvalho GB, Russell JO, Tufano RP, et al.Transoral thyroidectomy (TOETVA): complications, surgical time and learning curve. Oral Oncol. 2020 Nov;110:104871.

35. Luna-Ortiz K, Gomez-Pedraza A,Anuwong A. Lessons learned from the Transoral Endoscopic Thyroidectomy with Vestibular Approach (TOETVA) for the treatment of thyroid carcinoma. Ann Surg Oncol. 2020 May;27(5):1356-60.

36. Tae K. Robotic thyroid surgery. Auris Nasus Larynx. 2020 Jul 4 [Epub]. https://doi.org/10.1016/j.anl.2020.06.007.

37. Tae K, Kim KH. Transoral robotic selective neck dissection for papillary thyroid carcinoma: dissection of levels III and IV. Head Neck. 2020 Oct;42(10):3084-8.

38. Song CM, Park JS, Park HJ, Tae K. Voice outcomes of transoral robotic thyroidectomy: comparison with conventional trans-cervical thyroidectomy. Oral Oncol. 2020 Aug;107:104748.

39. Nakajo A, Arima H, Hirata M, Mizoguchi T, Kijima Y, Mori S, et al. Trans-Oral Video-Assisted Neck Surgery (TOVANS): a new transoral technique of endoscopic thyroidectomy with gasless premandible approach. Surg Endosc. 2013 Apr;27(4):1105-10.

40. Shan L, Liu J. A systemic review of transoral thyroidectomy. Surg Laparosc Endosc Percutan Tech. 2018 Jun;28(3):135-8.

41. Camenzuli C, SchembriWismayer P, Calleja Agius J.Transoral endoscopic thyroidectomy: a systematic review of the practice so far. JSLS. 2018 Jul-Sep;22(3):e2018.00026.

42. Tartaglia F, Maturo A, Di Matteo FM, De Anna L, Karpathiotakis M, Pelle F, et al. Transoral video assisted thyroidectomy: a systematic review. G Chir. 2018 Sep-Oct;39(5):276-83.

43. Chen S, Zhao M, Qiu J.Transoral vestibule approach for thyroid disease: a systematic review. Eur Arch Otorhinolaryngol. 2019 Feb; 276(2):297-304.

44. Ji YB, Ko SH, Song CM, Sung ES, Lee BJ,Wu CW, et al. Feasibility 
and efficacy of intraoperative neural monitoring in remote access robotic and endoscopic thyroidectomy. Oral Oncol. 2020 Apr;103: 104617.

45. Erol V, Dionigi G, Barczynski M, Zhang D, Makay O. Intraoperative neuromonitoring of the RLNs during TOETVA procedures. Gland Surg. 2020 Feb;9(Suppl 2):S129-35.

46. Dionigi G, Kim HY,Wu CW, Lavazza M, Materazzi G, Lombardi CP, et al. Neuromonitoring in endoscopic and robotic thyroidectomy. Updates Surg. 2017 Jun;69(2):171-9.

47. JiYB, Jeong JH,Wu CW, Chiang FY,Tae K. Neural monitoring of the external branch of the superior laryngeal nerve during transoral thyroidectomy. Laryngoscope. 2021 Feb;131(2):E671-6.

48. Barczynski M, Konturek A, Stopa M, Honowska A, Nowak W. Randomized controlled trial of visualization versus neuromonitoring of the external branch of the superior laryngeal nerve during thyroidectomy. World J Surg. 2012 Jun;36(6):1340-7.

49. Bellantone R, Boscherini M, Lombardi CP, Bossola M, Rubino F, De $\mathrm{Crea} \mathrm{C}$, et al. Is the identification of the external branch of the superior laryngeal nerve mandatory in thyroid operation? Results of a prospective randomized study. Surgery. $2001 \mathrm{Dec} ; 130(6): 1055-9$.

50. Lennquist S, Cahlin C, Smeds S. The superior laryngeal nerve in thyroid surgery. Surgery. 1987 Dec;102(6):999-1008.

51. Zhang D, Li S, Dionigi G, Zhang J,Wang T, Zhao Y, et al. Stimulating and dissecting instrument for transoral endoscopic thyroidectomy: proof of concept investigation. Surg Endosc. 2020 Feb;34(2):9961005.

52. Kim KN, Lee DW, Kim JY, Han KH, Tae K. Carbon dioxide embo- lism during transoral robotic thyroidectomy: a case report. Head Neck. 2018 Mar;40(3):E25-8.

53. Park EY, Kwon JY, Kim KJ. Carbon dioxide embolism during laparoscopic surgery. Yonsei Med J. 2012 May;53(3):459-66.

54. Kim CS, Kim JY, Kwon JY, Choi SH, Na S,An J, et al.Venous air embolism during total laparoscopic hysterectomy: comparison to total abdominal hysterectomy. Anesthesiology. 2009 Jul;111(1):50-4.

55. Kwek JW, Pang MJ, Heah HH. Pneumoperitoneum after transoral endoscopic thyroidectomy vestibular approach. Laryngoscope Investig Otolaryngol. 2020 May;5(3):580-3.

56. Tae K, Lee DW, Bang HS, Ahn YH, Park JH, Kim DS. Sensory change in the chin and neck after transoral thyroidectomy: prospective study of mental nerve injury. Head Neck. 2020 Nov;42(11):3111-7.

57. Zhang D, Fu Y, Dionigi G, Pontin A, Caruso E, Antonella P, et al. Human cadaveric model for studying the preservation of mental nerve during transoral endoscopic thyroidectomy. Surg Radiol Anat. 2020 Jan;42(1):55-62.

58. Yang HM, Shin KJ, Min J,Woo SH. Anatomical study of gasless transoral thyroidectomy and clinical application. Surg Endosc. 2020 Aug; 34(8):3414-23.

59. King SD, Arellano R, Gordon V, Olinger A, Seib CD, Duh QY, et al. Anatomic variations from 120 mental nerve dissections: lessons for transoral thyroidectomy. J Surg Res. 2020 Aug;256:P543-8.

60. Yi JW, Kim SJ, Lee KE. Evaluation of the efficacy of postoperative antibiotic treatment in transoral endoscopic thyroidectomy: a prospective randomised controlled trial. Br J Oral Maxillofac Surg. 2020 Apr;58(3):334-40. 